\title{
Thermal Diffusion Behavior of Nonionic Surfactants in Water
}

\author{
Hui Ning, ${ }^{\dagger}$ Rio Kita, ${ }^{\ddagger}, \$$ Hartmut Kriegs, ${ }^{\dagger}$ Jutta Luettmer-Strathmann," and Simone Wiegand $*$, \\ Forschungszentrum Jülich GmbH, IFF - Weiche Materie, D-52428 Jülich, Germany, Max Planck Institut für \\ Polymerforschung, Ackermannweg 10, D-55128 Mainz, Germany, Department of Physics, Tokai University, \\ Hiratsuka 259-1292, Japan, and Department of Physics, The University of Akron, Akron, Ohio 44325-4001
}

Received: December 14, 2005; In Final Form: April 10, 2006

\begin{abstract}
We studied the thermal diffusion behavior of hexaethylene glycol monododecyl ether $\left(\mathrm{C}_{12} \mathrm{E}_{6}\right)$ in water by means of thermal diffusion forced Rayleigh scattering (TDFRS) and determined Soret coefficients, thermal diffusion coefficients, and diffusion constants at different temperatures and concentrations. At low surfactant concentrations, the measured Soret coefficient is positive, which implies that surfactant micelles move toward the cold region in a temperature gradient. For $\mathrm{C}_{12} \mathrm{E}_{6} /$ water at a high surfactant concentration of $w_{1}=90 \mathrm{wt}$ $\%$ and a temperature of $T=25^{\circ} \mathrm{C}$, however, a negative Soret coefficient $S_{\mathrm{T}}$ was observed. Because the concentration part of the TDFRS diffraction signal for binary systems is expected to consist of a single mode, we were surprised to find a second, slow mode for $\mathrm{C}_{12} \mathrm{E}_{6} /$ water system in a certain temperature and concentration range. To clarify the origin of this second mode, we investigated also, tetraethylene glycol monohexyl ether $\left(\mathrm{C}_{6} \mathrm{E}_{4}\right)$, tetraethylene glycol monooctyl ether $\left(\mathrm{C}_{8} \mathrm{E}_{4}\right)$, pentaethylene glycol monododecyl ether $\left(\mathrm{C}_{12} \mathrm{E}_{5}\right)$, and octaethylene glycol monohexadecyl ether $\left(\mathrm{C}_{16} \mathrm{E}_{8}\right)$ and compared the results with the previous results for octaethylene glycol monodecyl ether $\left(\mathrm{C}_{10} \mathrm{E}_{8}\right)$. Except for $\mathrm{C}_{6} \mathrm{E}_{4}$ and $\mathrm{C}_{10} \mathrm{E}_{8}$, a second slow mode was observed in all systems usually for state points close to the phase boundary. The diffusion coefficient and Soret coefficient derived from the fast mode can be identified as the typical mutual diffusion and Soret coefficients of the micellar solutions and compare well with the independently determined diffusion coefficients in a dynamic light scattering experiment. Experiments with added salt show that the slow mode is suppressed by the addition of $w_{\mathrm{NaCl}}=0.02 \mathrm{~mol} / \mathrm{L}$ sodium chloride. This suggests that the slow mode is related to the small amount of absorbing ionic dye, less than $10^{-5}$ by weight, which is added in TDFRS experiments to create a temperature grating. The origin of the slow mode of the TDFRS signal will be tentatively interpreted in terms of a ternary mixture of neutral micelles, dye-charged micelles, and water.
\end{abstract}

\section{Introduction}

Surfactants in solution are used extensively in the production of food, pharmaceuticals, cosmetics, detergents, textiles, and paints, and are also important in enhanced oil recovery. Surfactant systems often exhibit interesting physicochemical properties due to the difference in chemical composition of the head and tail groups of the surfactant molecules. In the past three decades, nonionic surfactants of the general type $\mathrm{C}_{m} \mathrm{E}_{n}$, where $m$ indicates the number of $\mathrm{C}$ atoms in the alkyl chain (the tail), and $n$ represents the number of ethylene oxide units $\left(-\mathrm{OCH}_{2} \mathrm{CH}_{2}\right)_{n}-\mathrm{OH}$ in the headgroup, have been studied intensively. ${ }^{1}$ In aqueous solutions, these surfactants form a variety of structures, including spherical or elongated micelles, lamellae, and inverted micelles. The boundaries between different phases as well as the structure of the micelles in the micellar phase are determined by the hydrophilic/hydrophobic balance of $\mathrm{C}_{m} \mathrm{E}_{n}$ in water, which depends on temperature and concentration. ${ }^{1,2}$

Diffusion in a multicomponent fluid may be driven by composition, temperature, or pressure gradients. For mixtures subject to a temperature gradient at constant pressure, thermal diffusion, also known as Ludwig-Soret effect, leads to the

* Corresponding author. E-mail. s.wiegand@fz-juelich.de. Website: http://www.fz-juelich.de/iff/personen/S.Wiegand/.

Forschungszentrum Jülich GmbH.

Max Planck Institut für Polymerforschung.

$\S$ Department of Physics, Tokai University.

" Department of Physics, The University of Akron. formation of a concentration gradient. In the case of a binary mixture, the flux, $\mathbf{J}_{1}$, of one of the components in response to the temperature, $T$, and concentration, $w_{1}$, gradients may be written as ${ }^{3}$

$$
\mathbf{J}_{1}=-D\left(\rho \nabla w_{1}+\rho w_{1}\left(1-w_{1}\right) S_{\mathrm{T}} \nabla T\right)
$$

where $D$ is the translational mass diffusion coefficient, $S_{\mathrm{T}}$ the Soret coefficient, and $\rho$ the total mass density. The thermal diffusion coefficient $D_{\mathrm{T}}$ is related to the Soret and diffusion coefficients through $D_{\mathrm{T}}=D S_{\mathrm{T}}$. In the steady state of the system, where the flux $\mathbf{J}_{1}$ vanishes, the Soret coefficient describes the ratio of concentration and temperature differences along the direction of the gradient. We use the sign convention that the Soret coefficient is positive if the first named component is enriched in the colder region. ${ }^{4}$ Thermal diffusion has important applications, for example, in the separation of solutes. The effect is related to chemical and physical properties such as the mass of the molecules, the structure of the solutes, and chemical interactions. However, the microscopic mechanism of the effect is not yet completely understood, especially for complex systems.

In recent years, considerable experimental effort has been devoted to the thermodiffusion of complex molecular systems such as micellar phases of soluted surfactants, colloidal suspensions, and polymer solutions. ${ }^{5-11}$ Experiments $^{5,12}$ and theoretical calculations ${ }^{13,14}$ on the thermal diffusion behavior of micellar 
systems have mostly been carried out for ionic surfactant systems. Experiments yielded positive Soret coefficients of the micelles for all systems studied. Piazza and Guarino also investigated how the addition of salt changes the Soret effect and found that, in the dilute regime, the Soret coefficient decreased with increasing salt content, ${ }^{5}$ while the opposite is true for higher surfactant concentrations. They interpreted their findings in terms of the Debye screening length by using an interfacial tension mechanism proposed by Ruckenstein. ${ }^{15}$

Recently, we studied the thermal diffusion behavior of the nonionic surfactant $\mathrm{C}_{10} \mathrm{E}_{8}$ in water in a thermal diffusion forced Rayleigh scattering (TDFRS) experiment. ${ }^{16}$ The obtained Soret coefficients $S_{\mathrm{T}}$ were positive for all temperatures and concentrations, and the diffusion coefficients determined by TDFRS agreed with those obtained by dynamic light scattering (DLS). In the concentration and temperature range investigated in that work, $\mathrm{C}_{10} \mathrm{E}_{8} /$ water forms primarily elongated spherical micelles ${ }^{17}$ and undergoes no structural transitions. In the present work, we focus on the system $\mathrm{C}_{12} \mathrm{E}_{6}$ /water, which exhibits rich phase behavior and the coexistence of spherical and elongated micelles in a certain temperature and concentration range. ${ }^{18,19}$ We studied systematically the dependence of the transport coefficients on temperature, surfactant concentration, and salt concentration. Surprisingly, we found for this surfactant system a second mode in the TDFRS experiment in a certain temperature and concentration range. Since such a two-mode behavior has not been observed in micellar solutions before, we investigated several other surfactant systems in order to clarify the origin of the second mode. Surprisingly, we found for this and several other systems a second mode in the TDFRS experiment that has not been observed before.

The paper is organized as follows: in the next section, Section II, we present the working equations that are used to analyze the TDFRS experiments and explain an iterative procedure to correct for inadequacies of the electronic instrumentations. In the Experimental Section (Section III), we describe briefly the sample preparation, the experimental apparatus, and the determination of refractive index increments, which are necessary for the evaluation of the diffraction data. We discuss also the choice of dye, which is necessary to create a temperature gradient. In Section IV, we present thermal diffusion results for the $\mathrm{C}_{12} \mathrm{E}_{6}$ /water system for a range of temperatures and concentrations. For a very high surfactant concentration, where the surfactant forms inverted micelles in water, we observe a negative Soret coefficient for the surfactant, which is uncommon for micellar solutions. For lower surfactant concentrations, the Soret coefficients of $\mathrm{C}_{12} \mathrm{E}_{6} /$ water are positive. For a certain temperature and concentration range, we observed an unusual second mode in the TDFRS signal. Results of our investigation of several other surfactant systems $\left(\mathrm{C}_{6} \mathrm{E}_{4}, \mathrm{C}_{8} \mathrm{E}_{4}, \mathrm{C}_{12} \mathrm{E}_{5}\right.$, and $\mathrm{C}_{16} \mathrm{E}_{8}$ ), also presented in Section IV, allow us to relate the appearance of the mode to the distance from the boundary to the two-phase region. Furthermore, experiments on $\mathrm{C}_{12} \mathrm{E}_{6}$ with added salt show that the origin of the second, slow mode is ionic in nature. In Section $\mathrm{V}$, we summarize our results and present a tentative interpretation of the origin of the slow mode.

\section{Working Equations}

A. TDFRS. The diffraction efficiency of the optical grating created in a TDFRS experiment changes with time, $t$; a thermal grating is formed first and induces at later times a concentration grating. When the total intensity of the diffracted beam, $\zeta_{\text {het }}(t)$, is normalized to the thermal signal, the Soret coefficient, $S_{\mathrm{T}}$,

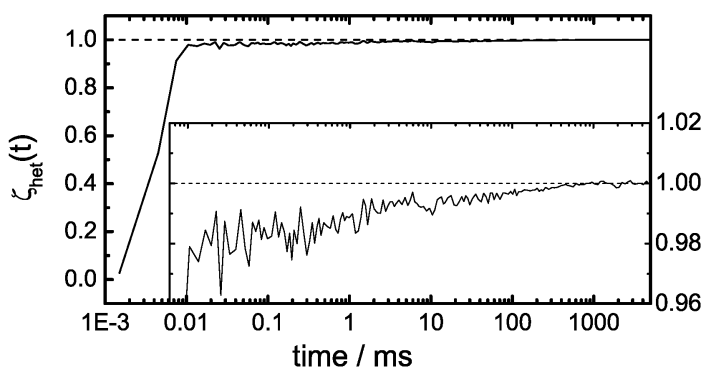

Figure 1. Measured excitation function in comparison with an ideal excitation function. Inset shows an enlargement of the plateau.

and the diffusion coefficient, $D$, may be determined from the amplitude and the time constant of $\xi_{\text {het }}(t)$, respectively,

$$
\zeta_{\text {het }}(t)=1+\left(\frac{\partial n}{\partial T}\right)_{w, p}^{-1}\left(\frac{\partial n}{\partial w_{1}}\right)_{T, p} S_{\mathrm{T}} w_{1}\left(1-w_{1}\right)\left(1-e^{-q^{2} D t}\right)
$$

The partial derivatives in eq 2 represent the increments of the refractive index, $n$, with temperature, $T$, and mass fraction, $w_{1}$ at constant pressure, $p$, and are measured separately. The scattering vector, $q$, is also determined independently.

Equation 2 describes a TDFRS signal with a single-mode decay. In some of the experiments on micellar solutions, a second, slower mode was also observed. The two-mode TDFRS signals were well described by the following expression for the normalized heterodyne intensity

$$
\begin{gathered}
\zeta_{\text {het }}(t)=1+\left(\frac{\partial n}{\partial T}\right)_{w_{1}, p}^{-1}\left(\frac{\partial n}{\partial w_{1}}\right)_{T, p} w_{1}\left(1-w_{1}\right) \\
\left(S_{\mathrm{Tf}} \times\left(1-e^{-q^{2} D_{\mathrm{f}} t}\right)+S_{\mathrm{Ts}} \times\left(1-e^{-q^{2} D_{\mathrm{s}} t}\right)\right),
\end{gathered}
$$

where the subscripts $\mathrm{f}$ and $\mathrm{s}$ stand for fast and slow mode, respectively, and where the decay times and the amplitudes of the two modes have been expressed in terms of two diffusion coefficients, $D_{\mathrm{f}}$ and $D_{\mathrm{s}}$, and two amplitude coefficients, $S_{\mathrm{Tf}}$ and $S_{\text {Ts }}$, respectively. Our results presented in Section IV show that the fast mode observed in solutions with two-mode decay is very similar to the single mode observed in solutions with onemode decay. This suggests that the coefficients $D_{\mathrm{f}}$ and $S_{\mathrm{Tf}}$ may be identified with the typical mutual diffusion and Soret coefficients of the micellar solutions.

The theory for TDFRS experiments assumes a step function for the excitation of the thermal grating. In actual experiments, this ideal excitation function is often not realized due to the limited rising time of the optical grating. Wittko and Köhler ${ }^{20}$ developed a method that takes this nonideality into account: in the course of an experiment, one measures both the TDFRS signal and the rise of the intensity in one of the fringes of the optical grating (see Section IIID). This rise in the intensity represents the actual excitation function of the thermal grating. The measured TDFRS signal and the measured excitation function are then deconvoluted in an iterative process to yield the "ideal" TDFRS signal. We extended the approach of Wittko and Köhler ${ }^{20}$ to the case of a two-mode decay and included error estimates and the corresponding weights in the fits to the measured signals. Figure 1 displays a typical excitation in comparison with the ideal step excitation function. The rising time for the optical grating to reach $98 \%$ of the final intensity value is on the order of $20 \mu \mathrm{s}$ and is followed by a slower increase of the intensity. The final value of the intensity is reached after $0.5 \mathrm{~s}$. Because the characteristics of the excitation 
function may change with time, it is necessary to measure the excitation function frequently between measurements.

B. DLS. The autocorrelation function of the scattered light intensity $g^{(2)}(q, t)$ is related to the normalized field correlation function $g^{(1)}(q, t)$ by

$$
g^{(2)}(q, t)=B\left(1+\beta\left|g^{(1)}(q, t)\right|^{2}\right)
$$

where $B$ and $\beta$ are the baseline and a constant related to the coherence of detection, respectively. ${ }^{21}$ Measured correlation functions were analyzed by the cumulant method to obtain an average decay rate $\bar{\Gamma}$,

$$
\ln \left|g^{(1)}(t)\right|=-\bar{\Gamma} t+\frac{\mu_{2}}{2 !} t^{2}-\frac{\mu_{3}}{3 !} t^{3}+\ldots
$$

where $\mu_{i}$ is the $i$ th cumulant and $\mu_{2} / \bar{\Gamma}^{2}$ gives the normalized dispersion of the distribution. When the fluctuation of the scattered light intensity is due to the translational diffusive motion of the solute molecules, the decay rate $\bar{\Gamma}$ is related to the translational diffusion coefficient through $D=\bar{\Gamma} / q^{2}$.

\section{Experiment}

A. Sample Preparation. Hexaethylene glycol monododecyl ether $\left(\mathrm{C}_{12} \mathrm{E}_{6}\right.$; purity $\left.\geq 98 \%\right)$ was ordered from Nikkol Chemicals, Tokyo. Tetraethylene glycol monohexyl ether $\left(\mathrm{C}_{6} \mathrm{E}_{4}\right.$; purity $=98.3 \%$ ) was purchased from Bachem AG, Switzerland. Pentaethylene glycol monododecyl ether $\left(\mathrm{C}_{12} \mathrm{E}_{5}\right.$; purity $\left.\geq 98 \%\right)$, tetraethylene glycol monooctyl ether $\left(\mathrm{C}_{8} \mathrm{E}_{4}\right.$; purity $\left.\geq 98 \%\right)$, and octaethylene glycol monohexadecyl ether $\left(\mathrm{C}_{16} \mathrm{E}_{8}\right.$; purity $\left.\geq 98 \%\right)$ were purchased from Fluka BioChemika, Japan. All surfactants were used without further purification.

To prepare the samples for the TDFRS experiment, a small amount of dye needs to be added to the samples. In the experiments, we used basantol yellow, ${ }^{22}$ a trivalent salt (cobalt complex), which was provided by BASF. Basantol yellow is delivered as an aqueous solution, which contains also small amounts of 2-(2-butoxyethoxy-)ethanol and 2,2'-dihydroxydipropyl ether. Drying the powder before adding it to the surfactant solution did not lead to a significant difference in the result. The optical density at $\lambda_{\mathrm{w}}$ was adjusted by addition of $0.001 \mathrm{wt} \%$ basantol yellow to $1.5-3 \mathrm{~cm}^{-1}$.

For the experiments, we first prepared an aqueous dye solution with the desired absorption by using deionized water (Milli-Q). Then the surfactant was added and stirred for $4 \mathrm{~h}$ at room temperature. For most of this work, we used solutions with less than $30 \mathrm{wt} \%$ surfactant (see Figure 8). However, for the $\mathrm{C}_{12} \mathrm{E}_{6}$ surfactant, experiments were also carried out at a high surfactant concentration (90 wt \%). After preparation, the solutions were filtered by a $0.45 \mu \mathrm{m}$ filter (Spartan) directly into the sample cells. For the TDFRS experiment, we used quartz cells (Hellma) with a layer thickness of $0.2 \mathrm{~mm}$. The sample cells were sealed tightly by a Teflon stopper. In the light scattering experiment, we used cylindrical glass cells with an inner diameter of $8.5 \mathrm{~mm}$. The optical path length of the cells used to determine the refractive index increment with temperature $(\partial n / \partial T)_{w, p}$ was $10 \mathrm{~mm}$.

B. Refractive Index Increments. The quantities $\left(\partial n / \partial w_{1}\right)_{T, p}$ for the surfactant systems were determined with a single measurement cell by means of a scanning Michelson interferometer operating at a wavelength of $632.8 \mathrm{~nm} .{ }^{20}$ In this way, we obtained $\left(\partial n / \partial w_{1}\right)_{T, p}=0.130$ at $T=25{ }^{\circ} \mathrm{C}$. Measurements with an Abbé refractometer between 20 and $40{ }^{\circ} \mathrm{C}$ confirmed this value and showed that $\left(\partial n / \partial w_{1}\right)_{T, p}$ is constant in the investigated temperature range $\left(\partial n / \partial w_{1}\right)_{T, p}=0.131 \pm 0.001$.

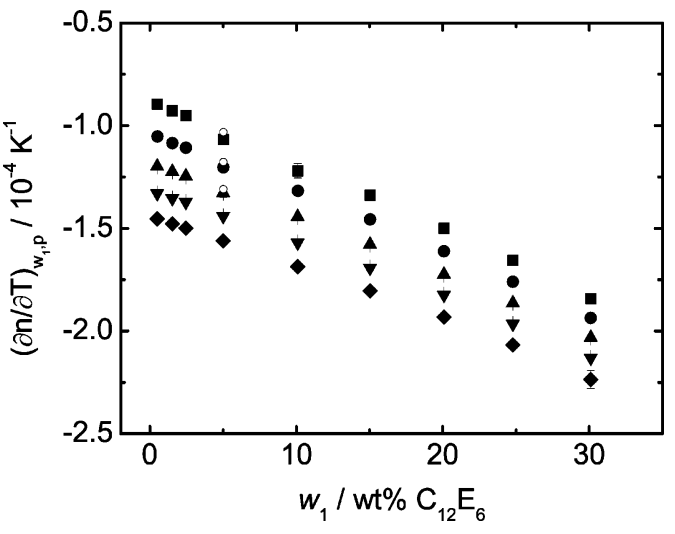

Figure 2. $(\partial n / \partial T)_{\mathrm{w}_{1}, \mathrm{p}}$ of $\mathrm{C}_{12} \mathrm{E}_{6}$ in water as a function of the surfactant concentration at $20{ }^{\circ} \mathrm{C}(\boldsymbol{\nabla}), 25{ }^{\circ} \mathrm{C}(\bullet), 30{ }^{\circ} \mathrm{C}(\boldsymbol{\Delta}), 35^{\circ} \mathrm{C}(\boldsymbol{\nabla})$, and 40 ${ }^{\circ} \mathrm{C}(\boldsymbol{)})$. The samples contained the same small amount of basantol yellow typically used in the TDFRS experiment. The open symbols refer to a measurement $\mathrm{C}_{12} \mathrm{E}_{6}\left(w_{1}=0.05\right)$ without dye. The error bars correspond to one standard deviation of the mean for repeated measurements; they barely exceed the symbol size.

Figure 2 shows the refractive index increments with temperature $(\partial n / \partial T)_{w_{1}, p}$ of $\mathrm{C}_{12} \mathrm{E}_{6}$ in water as a function of surfactant weight fraction at different temperatures. The samples used for the $(\partial n / \partial T)_{w_{1}, p}$ measurements came from the same batch as those samples measured in the TDFRS experiment and contained the same small amount of basantol yellow. The difference from a sample without dye is smaller than $1 \%$ (see open symbols in Figure 2). For the high surfactant concentration of $w_{1}=90 \mathrm{wt}$ $\%$, we measured $(\partial n / \partial T)_{w_{1}, p}=-3.71 \times 10^{-4} \mathrm{~K}^{-1}$ at $25^{\circ} \mathrm{C}$.

C. Dynamic Light Scattering. The dynamic light scattering (DLS) measurements were carried out for angles between $20^{\circ}$ and $120^{\circ}$. A Kr-ion laser was used as the light source (wavelength $\lambda=647.1 \mathrm{~nm}$ ). Correlation functions of scattered light were measured by an ALV-5000E correlator. The cylindrical sample cell was placed in a thermostated bath, which was controlled with an uncertainty of $0.1{ }^{\circ} \mathrm{C}$. The sample solutions were kept at the measured temperature for at least $30 \mathrm{~min}$ to ensure equilibrium conditions before starting data acquisition.

D. TDFRS. The experimental setup of TDFRS is sketched in Figure 3. The interference grating was written by an Ar-ion laser operating at the wavelength of $\lambda=488 \mathrm{~nm}$. The grating was read by a $\mathrm{He}-\mathrm{Ne}$ laser at $\lambda=632.8 \mathrm{~nm}$. The intensity of the diffracted beam was measured by a photomultiplier. A mirror mounted on a piezocrystal was used for phase shift and stabilization to obtain the heterodyne signal. The flip mirror M1 in front of the cell was used to image the diffraction grating on a CCD camera to determine the grating vector. The typical grating vector in the experiments was around $q=3100 \mathrm{~cm}^{-1}$ which corresponds to a fringe spacing around $d=20 \mu \mathrm{m}$. A second flip mirror M2 in front of the CCD camera was used to record the excitation function. For the measurement of the excitation function, a second fiber (multimode) was connected to the photomultiplier and the same recording equipment was used as for TDFRS measurements.

The TDFRS measurements were carried out in a temperature range from 20.0 to $40.0^{\circ} \mathrm{C}$. The temperature of the sample cell was thermostatically controlled by circulating water with an uncertainty of $0.02{ }^{\circ} \mathrm{C}$. Deterioration of the sample due to long heating and absorption of carbon dioxide leads to changes in the absorption spectrum. Therefore, we measured the absorption spectrum after each TDFRS experiment and discarded the samples when changes were significant.

E. Dye Influence on the TDFRS Signal. In this section, we study in more detail the influence of the added dye. Ideally, 


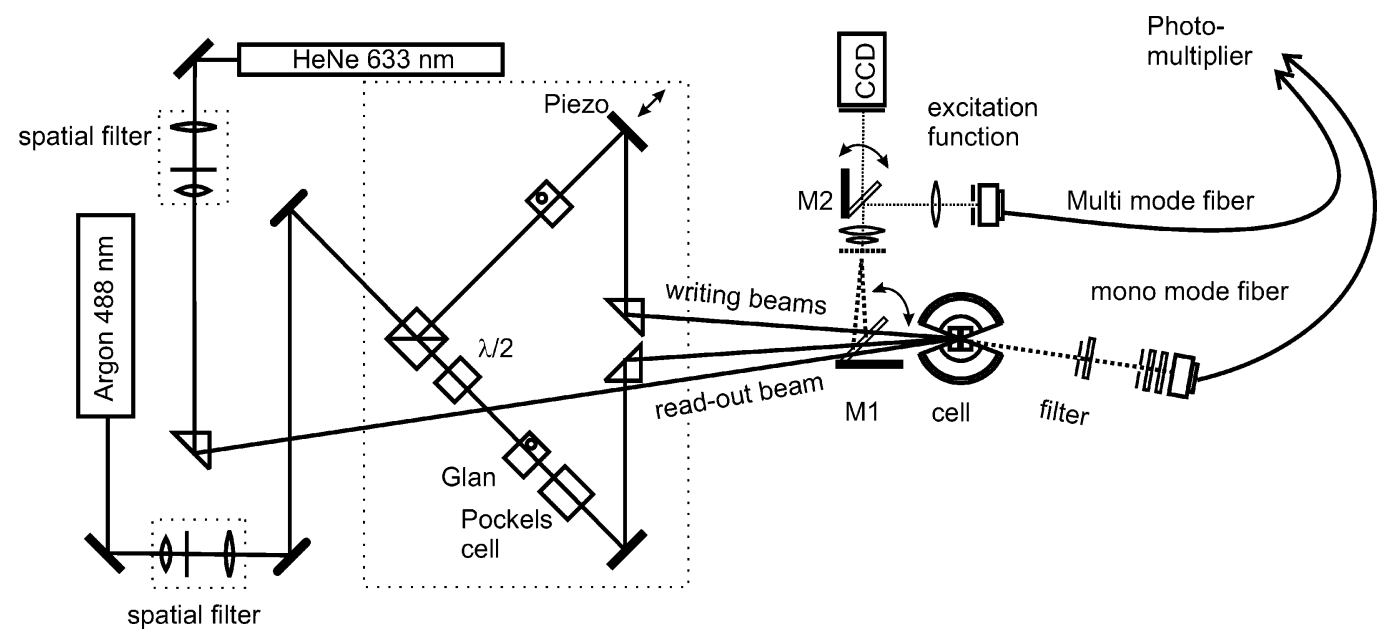

Figure 3. Schematic drawing of the TDFRS setup. The two flip mirrors, M1 and M2, and the multimode fiber serve to measure the excitation function of the optical grating.

the dye is inert, which means that there is no photobleaching and no dye contribution to the diffraction signal. For organic mixtures, it has been shown that the addition of an organic dye results in very small dye contributions to the signal (on the order of $0.5 \%$ ). These contributions do not influence the mean values of the transport coefficients but lead to slightly asymmetric error bars. ${ }^{20}$ In the case of aqueous systems, it is more difficult to find an inert dye. Typically, the spectroscopic properties of dyes depend on $\mathrm{pH}$, ionic strength, and other parameters. We investigated roughly 30 different water-soluble dyes. Of those, only basantol yellow and alizarin were inert with respect to the TDFRS experiment. Because of the strong $\mathrm{pH}$ dependence of the absorption spectrum of alizarin, and because alizarin is only soluble in the presence of the surfactant, we preferred basantol yellow and employed it throughout the experiments described here. Basantol yellow has already been used successfully in numerous studies on polymer solutions ${ }^{8,23}$ and with another nonionic surfactant system. ${ }^{16}$ As it turns out, this dye has a physical effect on the micelles of some of our nonionic surfactant systems. To separate these effects from potential spurious dye effects, we estimate in this section contributions of the dye itself to the TDFRS signal. Later, in Sections IV and $\mathrm{V}$, we investigate and discuss the effect of the dye on interactions between micelles.

As a first test, we measured the diffraction signal for five aqueous solutions of the dye. For an inert dye, there should be no concentration contribution to the signal but only a thermal contribution, which becomes identical with the excitation function at long times. Figure 4 shows a comparison of the excitation function for aqueous solutions of basantol yellow with various optical densities between 3.9 and $10 \mathrm{~cm}^{-1}$ at a wavelength $\lambda=488 \mathrm{~nm}$. The inset in Figure 4 shows a clear concentration contribution to the signal for the highest dye concentration. However, at typical dye concentrations, the amplitude of the concentration signal is very low and typically below $1 \%$ of the total signal. From the time dependence of the diffraction signal, we can also determine the thermal diffusivity of water. The extrapolated thermal diffusivity $D_{\text {th }}=1.37 \times$ $10^{-3} \mathrm{~cm}^{2} \mathrm{~s}^{-1}$ for an optical density of $2 \mathrm{~cm}^{-1}$ at a temperature of $T=25^{\circ} \mathrm{C}$ compares well with the literature value of $D_{\text {th }}=$ $1.45 \times 10^{-3} \mathrm{~cm}^{2} \mathrm{~s}^{-1}$ for water. ${ }^{24}$ From the concentration contribution to the TDFRS signal in aqueous dye solutions, we estimate that the contribution of the dye to the amplitude of the concentration signal for a measurement of the surfactant in water is typically below $0.5 \%$. Only for very low surfactant concentra-

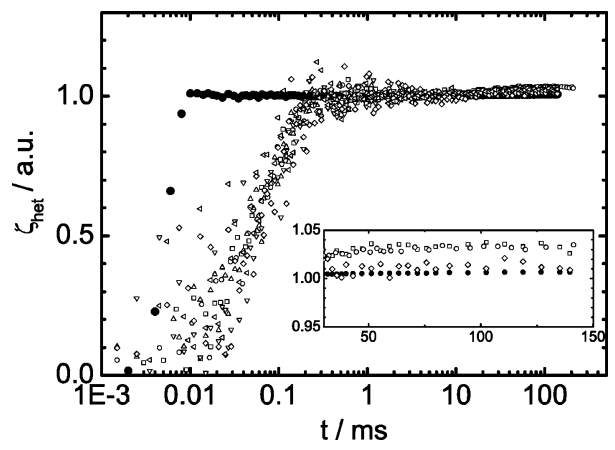

Figure 4. Excitation function $(\bullet)$ in comparison with heterodyne signal $\xi_{\text {het }}^{\text {dye }}$ of an aqueous solution of basantol yellow with various optical densities: $3.9 \mathrm{~cm}^{-1}(\diamond), 5 \mathrm{~cm}^{-1}(\nabla), 5.5 \mathrm{~cm}^{-1}$ (left open triangle), 7

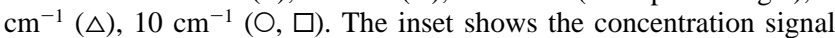
for the highest and lowest dye concentrations.

tions $\left(w_{1}<5\right.$ wt $\left.\%\right)$ is the contribution of the dye around $5 \%$. Because of the smallness of the dye contribution to the TDFRS signal, we neglect it in the following.

We also investigated the distribution of the dye in the micellar solutions. For $\mathrm{C}_{6} \mathrm{E}_{4}, \mathrm{C}_{8} \mathrm{E}_{4}, \mathrm{C}_{10} \mathrm{E}_{8}, \mathrm{C}_{12} \mathrm{E}_{5}, \mathrm{C}_{12} \mathrm{E}_{6}$, and $\mathrm{C}_{16} \mathrm{E}_{8}$, we prepared aqueous solutions with surfactant concentrations $w_{1}$ $=2.5 \%$ and for $\mathrm{C}_{6} \mathrm{E}_{4}$ with $w_{1}=5 \%$, which are above the critical micelle concentration. All solutions contained a typical amount of basantol yellow and were quenched by $3-5^{\circ} \mathrm{C}$ into the twophase region. After the temperature quench, we waited until the surfactant-rich and the water-rich phases had formed. In the case of the long-chain surfactant systems, $\mathrm{C}_{12} \mathrm{E}_{5}, \mathrm{C}_{12} \mathrm{E}_{6}$, and $\mathrm{C}_{16} \mathrm{E}_{8}$ /water, the color of the upper, surfactant-rich phase was a deep orange and that of the lower phase was colorless. For the shorter-chain surfactants $\mathrm{C}_{6} \mathrm{E}_{4}, \mathrm{C}_{8} \mathrm{E}_{4}$, and $\mathrm{C}_{10} \mathrm{E}_{8}$, the colors of the surfactant-rich and water-rich phases were a deeper and fainter orange, respectively. For $\mathrm{C}_{12} \mathrm{E}_{6}$, we also tested the effect of salt on the distribution of the dye and found that even an amount of salt that is sufficient to suppress the second mode (see Section IV.C.) does not change the color of the phases. For the $\mathrm{C}_{m} \mathrm{E}_{n}$ systems studied here, the dye distribution between the two phases reflects the surfactant concentration; the dye is enriched in the surfactant-rich phase and depleted in the waterrich phase. The surfactant concentration in the water-rich phase decreases rapidly with increasing chain length of the alkyl chains of the surfactants. ${ }^{25}$ Because the dye concentration in the waterrich phase, as indicated by the color of the phase, also decreases 


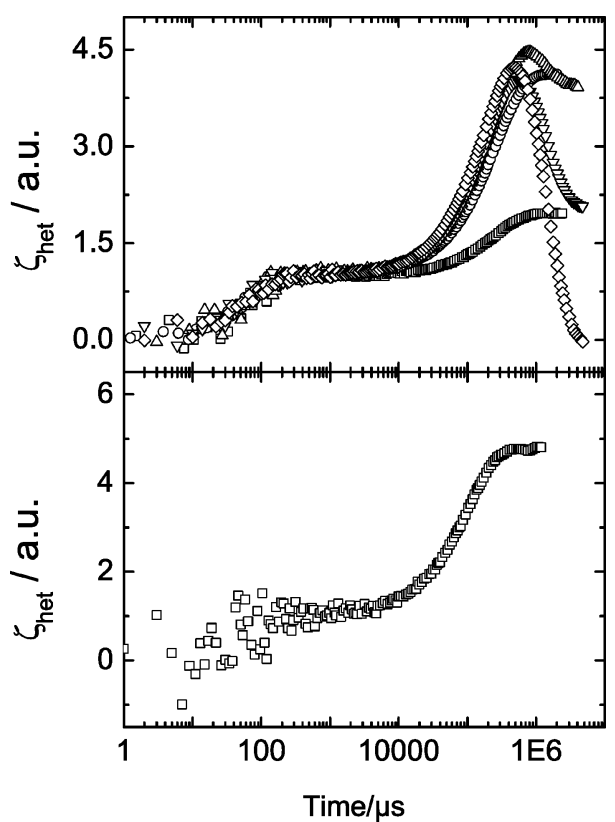

Figure 5. Normalized heterodyne signal $\zeta_{\text {het }}$ measured for $\mathrm{C}_{12} \mathrm{E}_{6}\left(w_{1}\right.$ $=5 \mathrm{wt} \%)$ at different temperatures $T=20^{\circ} \mathrm{C}(\square), 25^{\circ} \mathrm{C}(\mathrm{O}), 30^{\circ} \mathrm{C}$ $(\triangle), 35^{\circ} \mathrm{C}(\nabla)$, and $40{ }^{\circ} \mathrm{C}(\diamond)$ (upper figure) and $\mathrm{C}_{10} \mathrm{E}_{8}\left(w_{1}=15 \mathrm{wt}\right.$ $\%, T=20^{\circ} \mathrm{C}(\square)$ ) (lower figure), respectively.

rapidly with alkyl chain length, we conclude that the dye molecules are attracted to the surfactant molecules. Nevertheless, the temperature grating in the TDFRS experiment is not expected to be influenced by this attraction because, first of all, all experiments were performed in the homogeneous micellar $\mathrm{L}_{1}$ phase with a homogeneous surfactant distribution. Furthermore, we did not observe a shift of the absorption band to longer wavelength as has been observed for colloidal systems, where the dye molecules are preferentially adsorbed on the colloidal surface. ${ }^{26}$ This suggests that the constant exchange of surfactant molecules between micelles and solution prevents the formation of stable adsorbates.

As will be discussed in Section IV.B., we investigated the effect of the dye on the phase transition temperature for the $\mathrm{C}_{12} \mathrm{E}_{6} /$ water system and found that the dye increases the transition temperature for low surfactant concentrations. Because the change in the phase transition temperature is generally not large and decreases with increasing concentration, we do not expect a strong effect on the measured diffusion and Soret coefficients, except for dilute solutions very close to the phase boundary.

\section{Results}

In this section, we present the TDFRS results for $\mathrm{C}_{12} \mathrm{E}_{6}$ in water and compare them with results for other $\mathrm{C}_{m} \mathrm{E}_{n} /$ water systems. We start with a comparison of the measured diffraction signals of $\mathrm{C}_{12} \mathrm{E}_{6}$ with those obtained recently for $\mathrm{C}_{10} \mathrm{E}_{8} \cdot{ }^{16}$ In contrast to the previous measurements, we observed a second mode for $\mathrm{C}_{12} \mathrm{E}_{6}$ in water. Further analysis of the data shows that the diffusion coefficients determined from the fast mode agree well with the literature. In the following subsection, we discuss TDFRS signals for four more nonionic surfactant systems to establish patterns in the occurrence of the second mode. In the last subsection, we discuss the influence of salt on the second mode.

A. Characteristics of $\mathbf{C}_{\mathbf{1 2}} \mathbf{E}_{\mathbf{6}}$ in Water. Figure 5 displays normalized heterodyne signals for $\mathrm{C}_{12} \mathrm{E}_{6}$ and $\mathrm{C}_{10} \mathrm{E}_{8}$. For both surfactants, the signals are normalized to the thermal plateau,

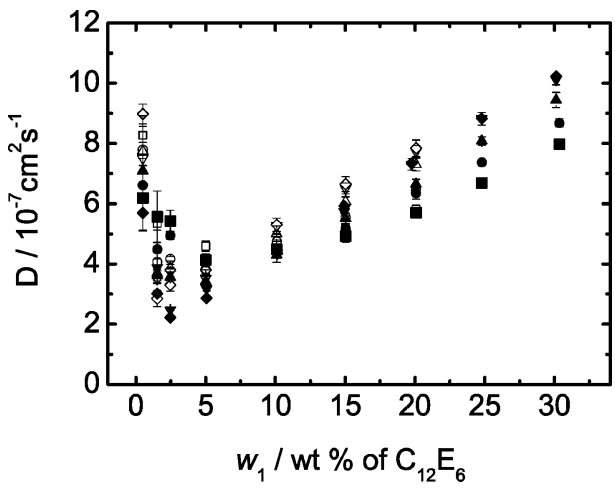

Figure 6. Diffusion coefficient of $\mathrm{C}_{12} \mathrm{E}_{6} /$ water in dependence of surfactant concentrations at different temperatures $T=20{ }^{\circ} \mathrm{C}(\boldsymbol{\square}, \square)$, $25^{\circ} \mathrm{C}(\bullet, \bigcirc), 30^{\circ} \mathrm{C}(\boldsymbol{\Delta}, \triangle), 35^{\circ} \mathrm{C}(\boldsymbol{\nabla}, \nabla)$, and $40{ }^{\circ} \mathrm{C}(\diamond, \diamond)$ determined by TDFRS (solid symbols) and DLS (open symbols). In the case of two-mode TDFRS signals, the data presented in this graph were determined from the fast mode. For both TDFRS and DLS measurements, the solutions contained basantol yellow.

which is reached at around $500 \mu \mathrm{s}$. The difference in the signals is quite striking. While in the case of $\mathrm{C}_{10} \mathrm{E}_{8}$, the diffraction intensity increases steadily before reaching its steady-state plateau, in the case of $\mathrm{C}_{12} \mathrm{E}_{6}$, the diffraction signal passes through a maximum and decays to the final equilibrium value. This two-mode behavior of the TDFRS signal is characteristic for $\mathrm{C}_{12} \mathrm{E}_{6}$ solutions at higher temperatures and lower surfactant concentrations (see Figure 8) and was not observed for concentrations above $w_{1}=25 \mathrm{wt} \%$ in the investigated temperature range.

As an independent test of our TDFRS results, we performed dynamic light scattering (DLS) experiments on $\mathrm{C}_{12} \mathrm{E}_{6}$ in water with and without added dye. We found that the addition of the dye did not lead to significant changes in the measured values for the mass diffusion coefficient $D$. Figure 6 shows DLS and TDFRS results for the diffusion coefficient of $\mathrm{C}_{12} \mathrm{E}_{6}$ for different temperatures as a function of concentration. In these experiments, the solutions for the DLS measurements contained the same amount of basantol yellow as the TDFRS samples. In the TDFRS experiments, the diffusion coefficients were derived from the fast mode. The results presented in Figure 6 show that the values obtained by the two different methods agree within experimental error, where the error bars correspond to one standard deviation.

The diffusion coefficient data in Figure 6 show a pronounced minimum at a weight fraction of about $w_{1}=2.5 \mathrm{wt} \%$. This is expected for mixtures near a phase boundary ${ }^{27}$ and agrees with earlier observations on this and related nonionic micellar solutions. ${ }^{19,28-30}$ For small surfactant concentrations, the diffusion coefficients decrease with increasing temperature, while the opposite is true for larger surfactant concentrations. In addition to the vicinity of the phase transition, micellar growth ${ }^{28}$ and the onset of entanglements between micelles ${ }^{31}$ are believed to contribute to the complicated composition and temperature dependence of the diffusion coefficients in micellar solutions.

Figure 7 provides a survey of the measured Soret coefficients $S_{\mathrm{T}}$, diffusion coefficients $D$, and thermal diffusion coefficients $D_{\mathrm{T}}$ of $\mathrm{C}_{12} \mathrm{E}_{6}$ in water as a function of the surfactant concentration $w_{1}$ at different temperatures. The data determined from the single mode in solutions with one-mode decay and from the fast mode in solutions with two-mode decay are represented by filled symbols in Figure 7 and are also presented in Table 1. Because their signals show the same characteristics, they will be referred to collectively as "fast mode" data. In the concentration range presented in Figure 7, the fast-mode Soret coefficients are 


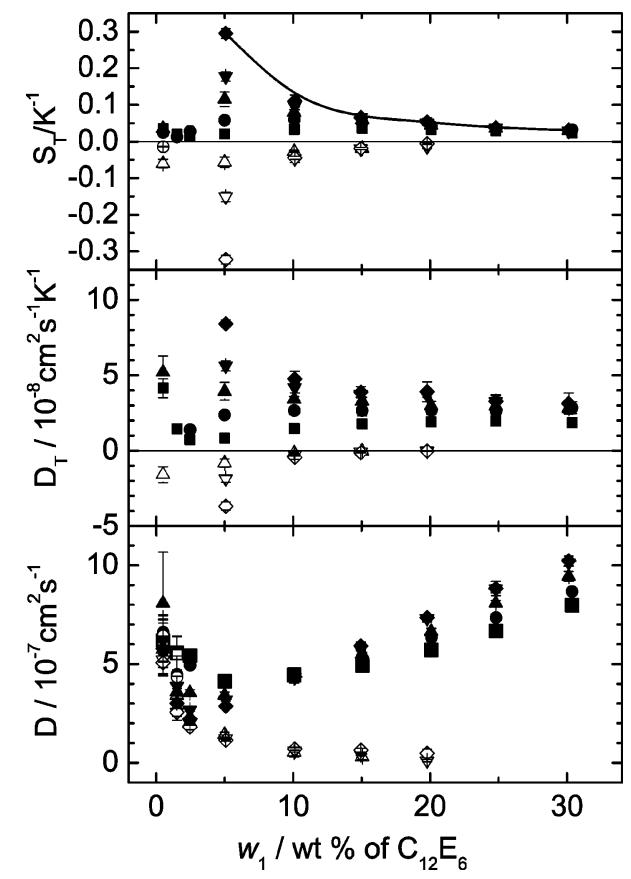

Figure 7. Soret coefficient $S_{\mathrm{T}}$, diffusion coefficient $D$, and thermal diffusion coefficient $D_{\mathrm{T}}$ of $\mathrm{C}_{12} \mathrm{E}_{6}$ in water in dependence of the surfactant concentration $w_{1}$ for different temperatures $T=20{ }^{\circ} \mathrm{C}(\boldsymbol{\square}$, $\square), 25^{\circ} \mathrm{C}(\bullet, \bigcirc), 30{ }^{\circ} \mathrm{C}(\Delta, \Delta), 35^{\circ} \mathrm{C}(\boldsymbol{\nabla}, \Delta)$, and $40{ }^{\circ} \mathrm{C}(\diamond, \diamond)$. The solid symbols refer to the fast mode and the open symbols to the second mode. The solid line in the top graph is a guide to the eye for the decreasing Soret coefficient with increasing concentration.

positive for all temperatures investigated. For concentrations 5 wt $\%<w_{1}<30$ wt $\%$, the $S_{\mathrm{T}}$ values decrease with increasing surfactant concentration. At its maximum near $w_{1}=5 \mathrm{wt} \%$, $S_{\mathrm{T}}$ increases strongly with temperature. The temperature dependence becomes less pronounced at higher concentrations, and at a concentration of $w_{1}=30 \mathrm{wt} \%$, the Soret coefficient is temperature independent within the experimental error. For concentrations smaller than 5 wt $\%$, the fast-mode Soret coefficients are quite small and show little dependence on temperature. Unfortunately, the data for very low concentrations are quite noisy due to the small amplitude of the concentration signals so that it is difficult to discern the concentration dependence in this range. Not shown in the figure is our result for a solution at high surfactant concentration, $w_{1}=90 \mathrm{wt} \%$, where inverted micelles form. For this concentration, the Soret coefficient $S_{\mathrm{T}}=-0.011 \pm 0.001$ is negative, indicating that the inverted micelles move to the warmer regions of the fluid.

The coefficients determined from the slow mode of the TDFRS signal are represented by open symbols in Figure 7. The diffusion coefficients associated with the slow mode decrease monotonically with increasing composition and approach zero as the amplitude of the slow modes vanishes near $20 \mathrm{wt} \%$. While the values of the slow-mode diffusion coefficients are comparable to those determined from the fast mode for low concentrations, they become markedly smaller for concentrations larger than $2.5 \mathrm{wt} \%$. Just as in the case of the fast mode, the amplitude of the slow mode decreases with decreasing temperature and increasing composition for intermediate compositions. However, the sign of the amplitude is negative, indicating that the species responsible for the mode is enriched in the warmer regions of the fluid. To interpret the slow-mode coefficients, we recall that TDFRS signals with twomode decays have previously been observed in ternary mixtures of a dilute polymer in mixed solvents. ${ }^{11}$ For ternary mixtures where cross effects between the two solutes can be neglected, the heterodyne signal intensity may be expressed as ${ }^{11}$

$$
\zeta_{\text {het }}(t)=1+\sum_{i=1,2}\left(\frac{\partial n}{\partial T}\right)_{w_{1}, w_{2}, p}^{-1}\left(\frac{\partial n}{\partial w_{i}}\right)_{T, p, w_{\mathrm{j} \neq \mathrm{i}}} w_{i}\left(1-w_{i}\right) S_{\mathrm{Ti}} \times
$$

where $i \in\{1,2\}$ denotes the solute species. This expression reduces to eq 3 , when the composition variations of the index of refraction are not sensitive to the solvent species, and when a prefactor $r=w_{2}\left(1-w_{2}\right) / w_{1}\left(1-w_{1}\right)$ is included in the definition of the second amplitude coefficient $S_{\mathrm{Ts}}$ in eq 3. Our discussion in Section $\mathrm{V}$ suggests that the inclusion of dye molecules in some micelles may be responsible for the slow mode. Such micellar solutions may be considered as ternary mixtures of regular micelles, dye-marked micelles, and water. In this case, the index of refraction changes are indeed expected to be insensitive to the micelle species, which justifies treating them as a common prefactor in eq 3. Because the dye concentration is extremely low and constant, the dye-marked micelles are dilute at all surfactant concentrations. This implies that cross-diffusion contributions to the decay times may be neglected and that the diffusion coefficients $D_{\mathrm{f}}$ and $D_{\mathrm{s}}$ may be associated with the mass diffusion of the regular micelles in water and the self-diffusion of the dye-marked micelles in the solution, respectively. While for high surfactant concentrations a cross contribution to the amplitudes cannot be excluded, cross diffusion effects are expected to be negligible for low surfactant concentrations. This implies that the amplitude coefficient $S_{\mathrm{Ts}}$ is closely related to the Soret coefficient of the dye-marked micelles. However, because the exact concentration of these micelles is not known, we have absorbed the parameter $r=$ $w_{2}\left(1-w_{2}\right) / w_{1}\left(1-w_{1}\right)$ in the value of the amplitude $S_{\mathrm{Ts}}$. Thus, the measured values of the Soret coefficients of the slow component differ from the actual values by a concentrationdependent factor and only qualitative conclusions can be drawn about the thermal diffusion behavior of this component.

B. Characteristics of Some Additional Nonionic Surfactant Systems. To gain a better understanding of the second slow process in the diffraction signal of the TDFRS experiment, we investigated other nonionic surfactants in water. Figure 8 shows the phase diagrams for the six investigated surfactants $\mathrm{C}_{6} \mathrm{E}_{4},{ }^{32}$ $\mathrm{C}_{8} \mathrm{E}_{4},{ }^{32} \mathrm{C}_{10} \mathrm{E}_{8},{ }^{33} \mathrm{C}_{12} \mathrm{E}_{5},{ }^{1} \mathrm{C}_{12} \mathrm{E}_{6},{ }^{1,18}$ and $\mathrm{C}_{16} \mathrm{E}_{8}{ }^{1}$ in water. The circles in Figure 8 mark the temperatures and concentrations of our measurements, where open and filled symbols indicate one- and two-mode behavior, respectively. The shape of the micelles just above the critical micelle concentration is highly dependent on surfactant type and solution conditions (concentration, electrolyte level, temperature). The systems with the smallest surfactant molecules $\mathrm{C}_{6} \mathrm{E}_{4}$ and $\mathrm{C}_{8} \mathrm{E}_{4}$ show a rather simple phase diagram with an isotropic micellar phase consisting of spherical micelles and a two-phase region. For $\mathrm{C}_{10} \mathrm{E}_{8}$ in the isotropic micellar phase $\left(\mathrm{L}_{1}\right)$, the shape of the micelles is somewhat elongated. ${ }^{17}$ In the case of $\mathrm{C}_{12} \mathrm{E}_{5}, \mathrm{C}_{12} \mathrm{E}_{6}$, and $\mathrm{C}_{16} \mathrm{E}_{8}$ in the $\mathrm{L}_{1}$ phase, the spherical micelles change their structure with increasing concentration to rodlike micelles, which entangle at high concentrations. ${ }^{31}$

There have been numerous studies of the effect of electrolytes on the phase separation in micellar solutions. ${ }^{35-41}$ The addition of salts may shift the phase boundary toward lower temperatures, as for example, in the case of sodium chloride, or toward higher temperatures, as for example, in the case of potassium iodide. ${ }^{41}$ Because basantol yellow is a trivalent salt, we determined its effect on the phase separation of $\mathrm{C}_{12} \mathrm{E}_{6} /$ water and found that it shifts the phase boundary by $\Delta T \approx 2.2{ }^{\circ} \mathrm{C}$ for a surfactant 
TABLE 1: Soret Coefficients, $S_{\text {th }}$, Thermal Diffusion Coefficient, $D_{\mathrm{T}}$, and Diffusion Coefficient, $D$, for $\mathrm{C}_{12} \mathbf{E}_{6} / \mathrm{Water}$ Containing Basantol Yellow as Dye ${ }^{a}$

\begin{tabular}{|c|c|c|c|c|c|}
\hline \multirow[b]{2}{*}{$w_{1}$} & \multicolumn{5}{|c|}{$S_{\mathrm{T}} / \mathrm{K}^{-1}$} \\
\hline & $20 \mathrm{~T} /{ }^{\circ} \mathrm{C}$ & $25 \mathrm{~T} /{ }^{\circ} \mathrm{C}$ & $30 \mathrm{~T} /{ }^{\circ} \mathrm{C}$ & $35 \mathrm{~T} /{ }^{\circ} \mathrm{C}$ & $40 \mathrm{~T} /{ }^{\circ} \mathrm{C}$ \\
\hline 0.005 & $0.035 \pm 0.003$ & $0.025 \pm 0.001$ & $0.036 \pm 0.010$ & & \\
\hline 0.015 & $0.020 \pm 0.002$ & $0.012 \pm 0.002$ & & & \\
\hline 0.025 & $0.014 \pm 0.001$ & $0.028 \pm 0.002$ & & & \\
\hline 0.050 & $0.021 \pm 0.002$ & $0.059 \pm 0.003$ & $0.115 \pm 0.020$ & $0.177 \pm 0.013$ & $0.294 \pm 0.013$ \\
\hline 0.101 & $0.033 \pm 0.003$ & $0.060 \pm 0.006$ & $0.078 \pm 0.008$ & $0.097 \pm 0.010$ & $0.110 \pm 0.016$ \\
\hline 0.150 & $0.036 \pm 0.002$ & $0.051 \pm 0.007$ & $0.060 \pm 0.004$ & $0.065 \pm 0.003$ & $0.066 \pm 0.007$ \\
\hline 0.201 & $0.034 \pm 0.002$ & $0.042 \pm 0.004$ & $0.045 \pm 0.004$ & $0.051 \pm 0.002$ & $0.053 \pm 0.010$ \\
\hline 0.248 & $0.030 \pm 0.002$ & $0.036 \pm 0.002$ & $0.037 \pm 0.006$ & $0.037 \pm 0.005$ & $0.037 \pm 0.004$ \\
\hline \multirow[t]{2}{*}{0.304} & $0.023 \pm 0.001$ & $0.033 \pm 0.004$ & $0.030 \pm 0.003$ & $0.029 \pm 0.002$ & $0.031 \pm 0.007$ \\
\hline & \multicolumn{5}{|c|}{$D_{\mathrm{T}} / 10^{-7} \mathrm{~cm}^{2} \mathrm{~s}^{-1} \mathrm{~K}^{-1}$} \\
\hline$w_{1}$ & $20 \mathrm{~T} /{ }^{\circ} \mathrm{C}$ & $25 \mathrm{~T} /{ }^{\circ} \mathrm{C}$ & $30 \mathrm{~T} /{ }^{\circ} \mathrm{C}$ & $35 \mathrm{~T} /{ }^{\circ} \mathrm{C}$ & $40 \mathrm{~T} /{ }^{\circ} \mathrm{C}$ \\
\hline 0.005 & $0.414 \pm 0.063$ & $9.562 \pm 5.081$ & $0.520 \pm 0.107$ & & \\
\hline 0.015 & $0.145 \pm 0.020$ & $2.641 \pm 1.355$ & & & \\
\hline 0.025 & $0.074 \pm 0.008$ & $0.140 \pm 0.008$ & & & \\
\hline 0.050 & $0.084 \pm 0.009$ & $0.238 \pm 0.012$ & $0.393 \pm 0.059$ & $0.562 \pm 0.034$ & $0.842 \pm 0.023$ \\
\hline 0.101 & $0.148 \pm 0.022$ & $0.267 \pm 0.025$ & $0.341 \pm 0.017$ & $0.419 \pm 0.036$ & $0.476 \pm 0.050$ \\
\hline 0.150 & $0.178 \pm 0.011$ & $0.265 \pm 0.034$ & $0.329 \pm 0.025$ & $0.373 \pm 0.016$ & $0.388 \pm 0.037$ \\
\hline 0.201 & $0.192 \pm 0.009$ & $0.268 \pm 0.026$ & $0.299 \pm 0.028$ & $0.369 \pm 0.015$ & $0.391 \pm 0.066$ \\
\hline 0.248 & $0.198 \pm 0.011$ & $0.264 \pm 0.016$ & $0.296 \pm 0.048$ & $0.325 \pm 0.045$ & $0.328 \pm 0.038$ \\
\hline \multirow[t]{2}{*}{0.304} & $0.185 \pm 0.011$ & $0.286 \pm 0.038$ & $0.281 \pm 0.034$ & $0.294 \pm 0.026$ & $0.313 \pm 0.069$ \\
\hline & \multicolumn{5}{|c|}{$D / 10^{-7} \mathrm{~cm}^{2} \mathrm{~s}^{-1}$} \\
\hline$w_{1}$ & $20 \mathrm{~T} /{ }^{\circ} \mathrm{C}$ & $25 \mathrm{~T} /{ }^{\circ} \mathrm{C}$ & $30 \mathrm{~T} /{ }^{\circ} \mathrm{C}$ & $35 \mathrm{~T} /{ }^{\circ} \mathrm{C}$ & $40 \mathrm{~T} /{ }^{\circ} \mathrm{C}$ \\
\hline 0.005 & $6.18 \pm 1.09$ & $6.62 \pm 0.88$ & $8.08 \pm 2.59$ & $6.20 \pm 1.07$ & $5.78 \pm 0.64$ \\
\hline 0.015 & $5.57 \pm 0.85$ & $4.49 \pm 0.94$ & $3.60 \pm 0.16$ & $3.88 \pm 0.51$ & $3.02 \pm 0.24$ \\
\hline 0.025 & $5.43 \pm 0.35$ & $4.94 \pm 0.13$ & $3.56 \pm 0.15$ & $2.67 \pm 0.06$ & $2.22 \pm 0.13$ \\
\hline 0.050 & $4.12 \pm 0.21$ & $4.06 \pm 0.07$ & $3.42 \pm 0.16$ & $3.18 \pm 0.07$ & $2.87 \pm 0.10$ \\
\hline 0.101 & $4.45 \pm 0.28$ & $4.43 \pm 0.14$ & $4.30 \pm 0.25$ & $4.34 \pm 0.10$ & $4.35 \pm 0.23$ \\
\hline 0.150 & $4.93 \pm 0.20$ & $5.17 \pm 0.16$ & $5.51 \pm 0.08$ & $5.73 \pm 0.06$ & $5.92 \pm 0.20$ \\
\hline 0.201 & $5.71 \pm 0.13$ & $6.35 \pm 0.20$ & $6.66 \pm 0.14$ & $7.31 \pm 0.19$ & $7.34 \pm 0.14$ \\
\hline 0.248 & $6.69 \pm 0.16$ & $7.37 \pm 0.08$ & $8.08 \pm 0.14$ & $8.82 \pm 0.21$ & $8.83 \pm 0.36$ \\
\hline 0.304 & $7.98 \pm 0.08$ & $8.68 \pm 0.14$ & $9.44 \pm 0.25$ & $10.12 \pm 0.18$ & $10.23 \pm 0.25$ \\
\hline
\end{tabular}

${ }^{a}$ In the presence of a second mode, all coefficients were determined from the fast mode.

concentration of $w=5 \mathrm{wt} \%$. The addition of $10^{-2} \mathrm{M}$ sodium chloride to the surfactant mixture with dye brings the system back to the original phase separation temperature. The temperature shift induced by basantol yellow is more pronounced at lower surfactant concentrations $\left(\Delta T \approx 5{ }^{\circ} \mathrm{C}\right.$ for $\left.w=2.5 \mathrm{wt} \%\right)$ but is still reversed by the addition of the same amount of salt.

The TDFRS results for all investigated nonionic surfactant systems of the type $\mathrm{C}_{m} \mathrm{E}_{n}$ are summarized in Figure 9, where we present the normalized heterodyne diffraction signals for these systems at a surfactant concentration of $w_{1}=2.5 \mathrm{wt} \%$ for three different temperatures. Except for $\mathrm{C}_{6} \mathrm{E}_{4}$ and $\mathrm{C}_{10} \mathrm{E}_{8}$, all surfactant systems show typical two-mode behavior: a positive concentration signal at shorter times followed by a slower process with negative amplitude, which is due to an inversion of the grating. The surfactant $\mathrm{C}_{12} \mathrm{E}_{5}$ in water shows the most distinct behavior: the second mode is so slow that the system had not reached the steady state after $5 \mathrm{~s}$.

C. Characteristics of the Surfactant Solutions in the Presence of Salt. To investigate the effect of ion concentration, we performed TDFRS experiments on surfactant solutions with added sodium chloride, a simple uncolored salt. Figure 10 shows the normalized heterodyne diffraction signal $\zeta_{\text {het }}$ for $\mathrm{C}_{12} \mathrm{E}_{6}$ and $\mathrm{C}_{16} \mathrm{E}_{8}$ in water at a surfactant concentration of $w_{1}=2.5 \mathrm{wt} \%$ and a temperature of $T=40{ }^{\circ} \mathrm{C}$ for several salt concentrations. For both surfactant systems, the second mode becomes weaker and finally disappears with increasing salt concentration. In Figure 11, we present the results for the fast- and slow-mode diffusion coefficients of $\mathrm{C}_{12} \mathrm{E}_{6} /$ water at a surfactant concentration of $w_{1}=2.5 \mathrm{wt} \%$ and a temperature of $T=40^{\circ} \mathrm{C}$ as a function of salt concentration. The results show that the fast-mode diffusion coefficients are almost independent of the salt content, while those determined from the slow mode decrease with increasing salt concentration until the slow mode disappears for higher salt contents $\left(w_{\mathrm{NaCl}}>0.02 \mathrm{~mol} / \mathrm{L}\right)$. Experiments with potassium chloride added to the surfactant solutions yielded results similar to those obtained with added sodium chloride.

\section{Discussion}

We have presented results from experiments on aqueous solutions of six nonionic surfactants of the type $\mathrm{C}_{m} \mathrm{E}_{n}$, where $m$ and $n$ indicate the number of repeat units in the alkyl tails and ethylene oxide headgroups, respectively. Most of the measurements were performed on solutions with surfactant concentrations of less than $30 \mathrm{wt} \%$. In this concentration range, the surfactants form nearly spherical or elongated micelles depending on the surfactant, the concentration, and the temperature. We also investigated one solution with very high surfactant concentration corresponding to inverted micelles.

Thermal diffusion forced Raleigh scattering (TDFRS) and dynamic light scattering (DLS) experiments were carried out to investigate thermal and mass diffusion in the surfactant systems. For typical micellar solutions, one expects the concentration part of the signal in a TDFRS experiment to consist of a single mode with positive amplitude (see bottom panel of Figure 5). Such single-mode signals were indeed observed for 

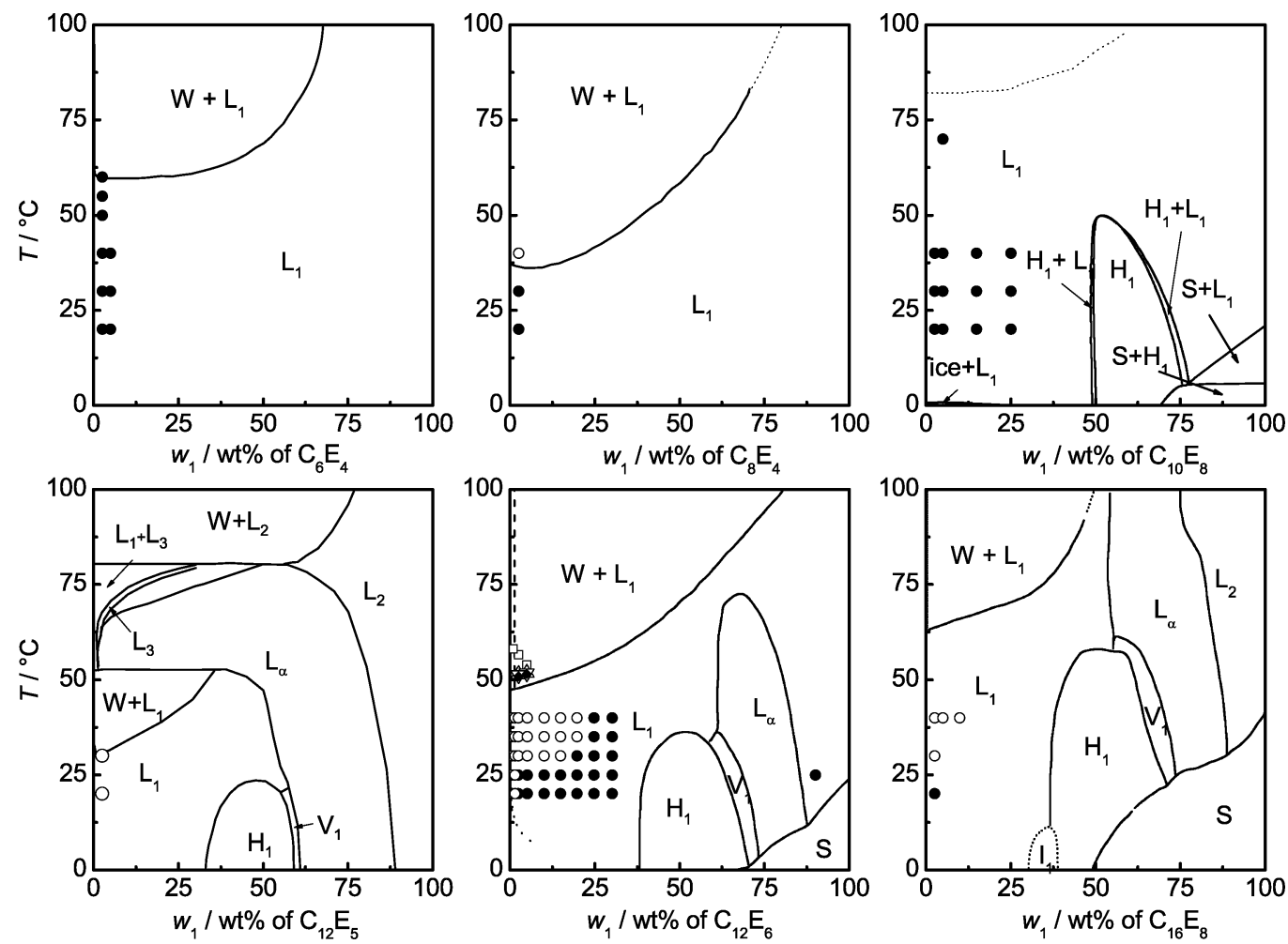

Figure 8. Schematic phase diagrams for $\mathrm{C}_{6} \mathrm{E}_{4},{ }^{32} \mathrm{C}_{8} \mathrm{E}_{4},{ }^{32} \mathrm{C}_{10} \mathrm{E}_{8},{ }^{33} \mathrm{C}_{12} \mathrm{E}_{5},{ }^{1} \mathrm{C}_{12} \mathrm{E}_{6},{ }^{1,18}$ and $\mathrm{C}_{16} \mathrm{E}_{8}{ }^{1}$ in water. The different regions are abbreviated in the following way: water $(\mathrm{W})$, micellar solution $\left(\mathrm{L}_{1}\right)$, isotropic solution not fully miscible with water or surfactant $\left(\mathrm{L}_{2}\right)$, hexagonal $\left(\mathrm{H}_{1}\right)$, lamellar $\left(\mathrm{L}_{\alpha}\right)$, bicontinuous cubic $\left(\mathrm{V}_{1}\right)$, coexisting phase $\left(\mathrm{W}+\mathrm{L}_{1}\right)$, solid surfactant phase $(\mathrm{S})$, and close packed spherical micelle phase $\left(\mathrm{I}_{1}\right)$. The two-phase region for $\mathrm{C}_{10} \mathrm{E}_{8}$ /water is indicated only by a dotted line because only the cloud point temperature is available in the literature. ${ }^{34}$ The dashed line in the phase diagram of $\mathrm{C}_{12} \mathrm{E}_{6}$ /water refers to the percolation line given by Strey and Pakusch. ${ }^{18}{ }^{\text {For }} \mathrm{C}_{12} \mathrm{E}_{6} /$ water, we determined also the phase separation temperature at two surfactant concentrations $(\nabla)$, and also for the same solutions containing basantol yellow ( $\square$ ), sodium chloride $(\diamond)$, and basantol yellow + sodium chloride $(\triangle)$. The open and solid circles mark the concentration and temperature range where TDFRS experiments have been performed. Depending on the system, temperature, and concentration, either one-mode $(\bullet)$ or two-mode behavior $(O)$ has been observed.

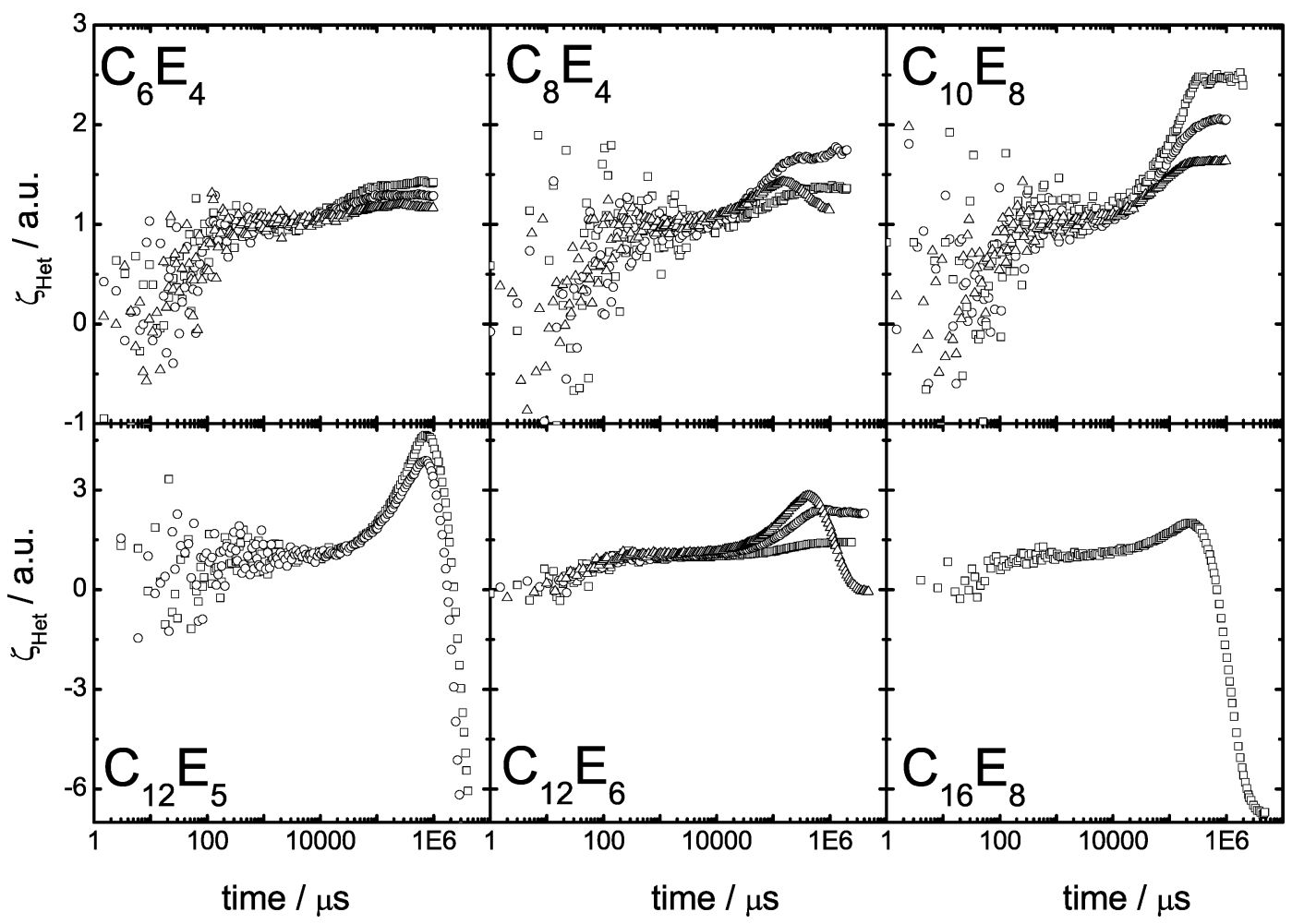

Figure 9. Normalized heterodyne signals $\xi_{\text {het }}$ measured for $\mathrm{C}_{6} \mathrm{E}_{4}, \mathrm{C}_{8} \mathrm{E}_{4}, \mathrm{C}_{12} \mathrm{E}_{5}, \mathrm{C}_{12} \mathrm{E}_{6}$, and $\mathrm{C}_{16} \mathrm{E}_{8}$ in water at different temperatures $\left(T=20{ }^{\circ} \mathrm{C}(\square)\right.$, $\left.30{ }^{\circ} \mathrm{C}(\mathrm{O}), 40{ }^{\circ} \mathrm{C}(\triangle)\right)$. For all systems, the surfactant concentration was $w_{1}=2.5 \mathrm{wt} \%$.

part of the micellar solutions investigated in this work. The values of the Soret coefficients determined from these signals are positive, and the mass diffusion coefficients agree with those obtained from dynamic light scattering (DLS) within experi- 


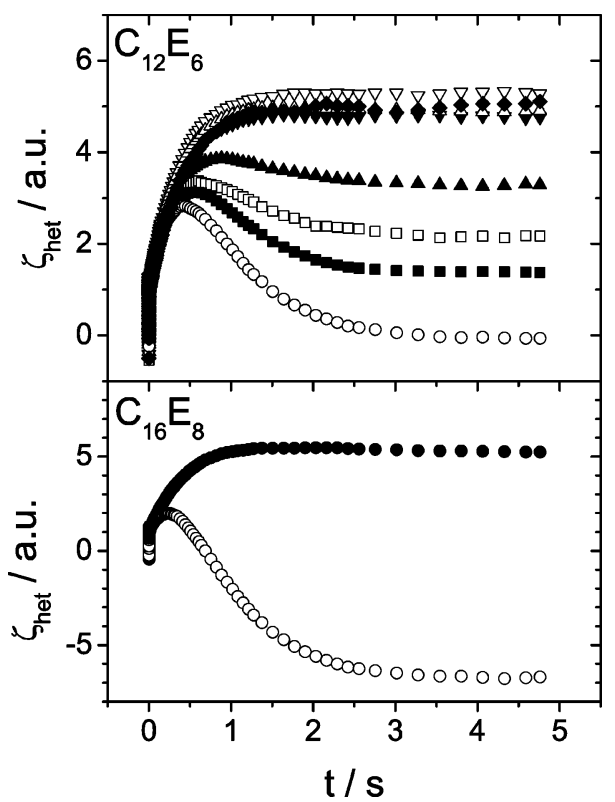

Figure 10. Normalized heterodyne signal $\xi_{\text {het }}$ measured for $\mathrm{C}_{12} \mathrm{E}_{6}$ and $\mathrm{C}_{16} \mathrm{E}_{8}$ in water at a temperature of $T=40{ }^{\circ} \mathrm{C}$. For both systems, the surfactant concentration was $w_{1}=2.5 \mathrm{wt} \%$, and the solutions contained basantol yellow as dye. $\mathrm{C}_{12} \mathrm{E}_{6}$ was studied for different sodium chloride concentrations $w_{\mathrm{NaCl}}(0.0 \mathrm{~mol} / \mathrm{L}(\mathrm{O}), 0.00092 \mathrm{~mol} / \mathrm{L}(\mathbf{\square}), 0.0018 \mathrm{~mol} / \mathrm{L}$ $(\square), 0.0037 \mathrm{~mol} / \mathrm{L}(\mathbf{\Delta}), 0.018 \mathrm{~mol} / \mathrm{L}(\triangle), 0.023 \mathrm{~mol} / \mathrm{L}(\boldsymbol{\nabla}), 0.037 \mathrm{~mol} / \mathrm{L}$ $(\nabla), 0.053 \mathrm{~mol} / \mathrm{L}(\diamond)) . \mathrm{C}_{16} \mathrm{E}_{8}$ was studied with $(0.149 \mathrm{~mol} / \mathrm{L}(\bullet))$ and without salt $(O)$.

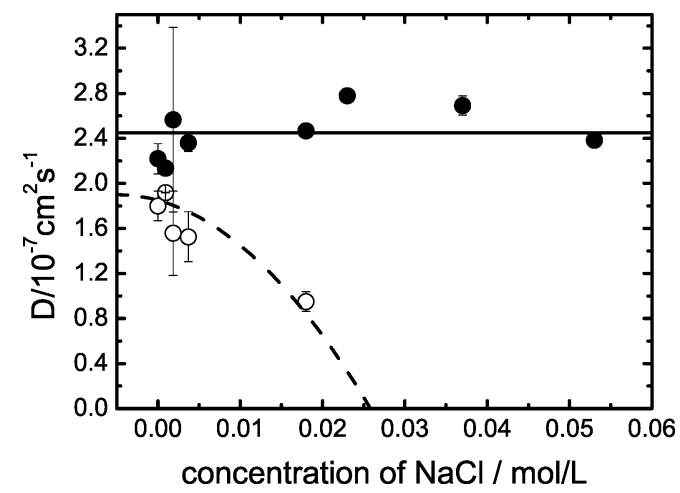

Figure 11. Diffusion coefficient, $D$, derived from the fast $(\bullet)$ and second slow (O) mode for $\mathrm{C}_{12} \mathrm{E}_{6} /$ water $\left(w_{1}=2.5 \mathrm{wt} \%, T=40{ }^{\circ} \mathrm{C}\right)$ in dependence of sodium chloride concentration. The solid line represents the mean diffusion constant for all salt concentrations. The dashed line is a guide to the eye.

mental errors. For other solutions, however, we observed a second mode in the TDFRS concentration signal (see top panel of Figure 5). The second mode always had a negative amplitude and a long decay time, corresponding to a negative Soret coefficient and a small mass diffusion coefficient. DLS experiments on the same systems showed no second mode and yielded mass diffusion coefficients that agree well with those obtained from the fast mode of the TDFRS signal.

The TDFRS signals at surfactant concentration $w_{1}=2.5 \mathrm{wt}$ $\%$ presented in Figure 9 are representative of the behavior of the different surfactants. For the temperatures and concentrations investigated in this work, only single-mode TDFRS signals have been recorded for $\mathrm{C}_{6} \mathrm{E}_{4}$ and $\mathrm{C}_{10} \mathrm{E}_{8}$, only two-mode signals for $\mathrm{C}_{12} \mathrm{E}_{5}$, and both one- and two-mode signals for $\mathrm{C}_{8} \mathrm{E}_{4}, \mathrm{C}_{12} \mathrm{E}_{6}$, and $\mathrm{C}_{16} \mathrm{E}_{8}$, respectively. In general, the thermodynamic states associated with two-mode behavior (indicated by open circles in Figure 8) are closer to the miscibility gap than those associated with single-mode behavior (shown as filled circles).
This suggests that single-mode signals will be observed in all micellar solutions at sufficiently high concentrations and low temperatures. For the system $\mathrm{C}_{10} \mathrm{E}_{8} /$ water, only single-mode behavior has been observed in this work; however, the high phase transition temperature prohibits measurements closer to the phase boundary, where two-mode behavior may be found. For the smallest surfactant, $\mathrm{C}_{6} \mathrm{E}_{4}$, a careful investigation of states near the phase boundary revealed no two-mode behavior.

Our results presented in Section IV.A. show that the fast mode observed in solutions with two-mode decay is very similar to the single mode observed in solutions with one-mode decay. The diffusion coefficients extracted from these modes agree within experimental error with our DLS results for the same solutions. Furthermore, the Soret coefficients extracted from the fast and single modes show similar temperature and composition dependence. This confirms that the fast-mode coefficients $D_{\mathrm{f}}$ and $S_{\mathrm{Tf}}$ introduced in Section II may be identified as the typical mutual diffusion and Soret coefficients of the micellar solutions.

To investigate the temperature and composition dependence of the typical transport coefficients in detail, measurements were performed on the system $\mathrm{C}_{12} \mathrm{E}_{6} /$ water for surfactant concentrations between $0.5 \mathrm{wt} \%$ and $30 \mathrm{wt} \%$ and temperatures between 20 and $40{ }^{\circ} \mathrm{C}$. In agreement with literature results, the values of $D$ have a minimum near the critical phase separation concentration of about 2.5 wt \% (see Figure 6). The temperature and concentration dependence of the diffusion coefficients is believed to reflect both the distance to the phase boundary and the changes in micellar structure with composition and temperature. ${ }^{19,28-31}$ The Soret coefficients $S_{\mathrm{T}}$ and the thermal diffusion coefficients $D_{\mathrm{T}}$ derived from the fast mode and single modes are positive, as has been observed before for ionic and nonionic surfactant solutions. 5,12,16 They have their maximum values and their largest temperature dependence near the concentration where $D$ is at minimum (see Figure 7). An increase in the thermal diffusion coefficients with temperature has also been observed in solutions of poly(ethylene oxide) (PEO) in water ${ }^{11}$ and may be associated with the approach to the lower critical solution temperature. Just as in the case of PEO in water, the ethylene oxide groups of the surfactants form hydrogen bonds with the water molecules, which leads to a decrease in solubility at higher temperatures. Our results for the solution with high surfactant concentration $\left(w_{1}=90 \mathrm{wt} \%\right)$ showed, for the first time, a negative value for the Soret coefficient of a micellar solution. At this high surfactant concentration, the micelles in solution are inverted so that the water and ethylene oxide chains are on the inside of the micelles and the alkyl chains are on the outside. Because the water concentration is low, the hydrogen bond formation between ethylene oxide chains and water molecules may not be the dominant factor in determining the Soret effect anymore. Furthermore, the difference in surface structure between regular and inverted micelles may contribute to their different thermal diffusion behavior. ${ }^{42}$

A second, slow mode has not been observed before in micellar solutions, and its origin is not immediately clear. Slow modes have been observed, however, in light scattering experiments on polyelectrolyte solutions at sufficiently high polyelectrolyte and sufficiently low salt concentrations. ${ }^{43,44}$ In these solutions, the slow-moving species has been identified with temporal aggregates of macroions. ${ }^{44-46}$ The origin of the aggregation in polyelectrolyte solutions is attributed to a net attractive interaction between polyions in solutions above a minimum polyion concentrations. For smaller concentrations, on the other hand, the charged chains repel each other, which prohibits aggrega- 
tion. ${ }^{46-48}$ Two-mode TDFRS signals have previously been observed only in experiments on ternary mixtures consisting of a polymer at low concentration in a mixed solvent. ${ }^{11}$

As in the case of the polyelectrolytes, ${ }^{44}$ we find that addition of salt decreases the amplitude of the slow mode until it is completely suppressed at sufficiently high salt concentrations (see Figure 10). The only source of free ions in our experiments is the dye basantol yellow, a trivalent salt, that is added in small amounts to the micellar solutions when TDFRS experiments are performed. Temperature quench experiments into the coexistence region of micelle-rich and water-rich phases show that the dye is enriched in the micelle-rich phase and present in the water-rich phase only in proportion to the low surfactant concentration. This leads to the conclusion that the dye molecules associate with the surfactant molecules.

Cloud point experiments on the system $\mathrm{C}_{12} \mathrm{E}_{6}$ /water show that the presence of the dye increases the phase transition temperature (see Figure 8). This effect is reversed, and the original phase boundary restored, when salt, in an amount sufficient to suppress the slow mode, is added to the dye-containing micellar solutions. The addition of salt by itself has very little effect on the phase boundary. These results show that the dye stabilizes the micelles in solutions and that this stabilizing effect is related to the ionic nature of the dye. Because an increase in the phase transition temperature is associated with a decrease in the attractive interactions between the micelles, ${ }^{17,18}$ one concludes that the dye molecules introduce a repulsive interaction between the micelles.

The experimental results for the slow mode of the TDFRS signal may tentatively be interpreted in terms of a ternary mixture of neutral micelles, charged micelles, and water, if one assumes that at least part of the dye molecules are incorporated into micelles. This is a reasonable assumption because the dye molecules may act as cosurfactants and nucleate the growth of micelles. In general, one would expect an equilibrium between dye molecules incorporated in micelles and dye molecules in solution, where the activity constant depends on composition, temperature, and type of surfactant. While micelles that contain dye molecule are negatively charged, they will not interact with each other through electrostatic interactions because their separation is much larger than the Debye screening length. Hence, the aggregation mechanism that gives rise to the slow mode in polyelectrolyte solutions does not apply to our micellar solutions. The diffusion coefficients associated with the slow mode decrease monotonically with increasing composition and approach zero as the amplitude of the slow modes vanishes. The temperature and composition dependence of the slow-mode diffusion coefficients is closely correlated with the viscosity ${ }^{25}$ of the micellar solutions and suggests that the size of the dyecharged micelles does not change much with composition. This size is typically around 5-6 nanometers and falls in the range of the size distribution of the regular micelles, which are quite polydisperse. This would explain why a slow mode is not observed in the DLS experiments. The Soret coefficients derived from the slow modes are negative, indicating that the dyecharged micelles are enriched in the warmer regions of the fluid. This is consistent with our finding that the presence of the dye introduces a repulsive interaction between micelles.

While the discussion presented here is tentative, our results suggest that it may be interesting to investigate in a more systematic way nonionic surfactants that are doped with varying amounts of charge carrying surfactant molecules.

Acknowledgment. We would like to thank Wim Briels and Gerhard Wegner for their kind support, and Beate Müller for her experimental assistance. We are very much indebted to Gerhard Wittko, who made his program code available to us. We thank Malte Kleemeier for many discussions and for carefully reading the manuscript. We are grateful for many fruitful discussions with Jan Dhont, Peter Lang, Reinhard Strey and Remco Tuinier. This work was partially supported by the Deutsche Forschungsgemeinschaft grant Wi 1684.

\section{References and Notes}

(1) Mitchell, D. J.; Tiddy, G. J. T.; Waring, L.; Bostock, T.; McDonald, M. P. J. Chem. Soc., Faraday Trans. 1 1983, 79, 975.

(2) Schick, M. Nonionic Surfactants: Physical Chemistry; Marcel Dekker. Inc.: New York and Basel, 1987; Vol. 23.

(3) Tyrell, H. Diffusion and Heat Flow in Liquids; Butterworth: London, 1961.

(4) Köhler, W., Wiegand, S., Eds. Thermal Nonequilibrium Phenomena in Fluid Mixtures; Springer: Berlin, 2002; Vol. LNP584.

(5) Piazza, R.; Guarino, A. Phys. Rev. Lett. 2002, 88, 208302.

(6) Lenglet, J.; Bourdon, A.; Bacri, J. C.; Demouchy, G. Phys. Rev. E 2002, 65, 031408 .

(7) Blums, E.; Odenbach, S.; Mezulis, A.; Maiorov, M. Phys. Fluids 1998, 10, 2155.

(8) de Gans, B.; Kita, R.; Wiegand, S.; Luettmer-Strathmann, J. Phys. Rev. Lett. 2003, 91, 245501.

(9) Rauch, J.; Köhler, W. Phys. Rev. Lett. 2002, 88, 185901.

(10) Zhang, K.; Briggs, M.; Gammon, R.; Sengers, J.; Douglas, J. J. Chem. Phys. 1999, 111, 2270.

(11) Kita, R.; Wiegand, S.; Luettmer-Strathmann, J. J. Chem. Phys. 2004, $121,3874$.

(12) Leaist, D. G.; Hui, L. J. Phys. Chem. 1989, 93, 7547.

(13) Takeyama, N.; Nakashima, K. J. Phys. Soc. Jpn. 1993, 62, 2180.

(14) Fayolle, S.; Bickel, T.; Boiteux, S. L.; Würger, A. Phys. Rev. Lett. 2005, 95, 208301.

(15) Ruckenstein, E. J. Colloid Interface Sci. 1981, 83, 77.

(16) Ning, H.; Kita, R.; Wiegand, S. Prog. Colloid Polym. Sci. 2005, accepted.

(17) Kleshchanok, D.; Strunk, H.; Tuinier, R.; Lang, P. Phys. Chem. Chem. Phys. 2006, 8, 869.

(18) Strey, R.; Pakusch, A. In Proceedings of the 5th International Symposium on Surfactant in Solution, Mittal, K., Bothorel, P., Eds.; Plenum: New York, 1986; pp 465-472.

(19) Thomas, H. G. Lomakin, A.; Blankschtein, D.; Benedek, G. B. Langmuir 1997, 13, 209.

(20) Wittko, G.; Köhler, W. Philos. Mag. 2003, 83, 1973.

(21) Berne, B.; Pecora, R. Dynamic Light Scattering; John Wiley \& Sons: New York, 1976.

(22) Basantol gelb 215 is a registered tradename of BASF. It is a trivalent salt soluble in water with a strong absorption around $480 \mathrm{~nm}$.

(23) Kita, R.; Wiegand, S. Macromolecules 2005, 38, 4554.

(24) Abramson, E. H.; Brown, J. M.; Slutsky, L. J. J. Chem. Phys. 2001, 115,10461

(25) Strey, R. Ber. Bunsen-Ges. Phys. Chem. 1996, 100, 182.

(26) de Gans, B.-J.; Kita, R.; Müller, B.; Wiegand, S. J. Chem. Phys. 2003, 118, 8073.

(27) Tyrrell, H. J. V.; Harris, K. R. Diffusion in Liquids; Butterworths: London, 1984.

(28) Brown, W.; Rymdén, R. J. Phys. Chem. 1987, 91, 3565.

(29) Wilcoxon, J. P.; Kaler, E. W. J. Chem. Phys. 1987, 86, 4684.

(30) Wilcoxon, J. P.; Schaefer, D. W.; Kaler, E. W. J. Chem. Phys. 1989, 90, 1909.

(31) Carale, T. R.; Blankschtein, D. J. Phys. Chem. 1992, 96, 459.

(32) van Os, N.; Haak, J.; Rupert, L. Physicochemical Properties of Selected Anionic, Cationic, and Nonionic Surfactants; Elsevier: Amsterdam, 1993.

(33) Nibu, Y.; Inoue, T. J. Colloid Interface Sci. 1998, 205, 305.

(34) Cox, K.; Benson, H. Fluid Phase Equilib. 1986, 30, 173.

(35) Kahlweit, M.; Lessner, E.; Strey, R. J. Phys. Chem. 1984, 88, 1937.

(36) Firman, P.; Haase, D.; Jen, J.; Kahlweit, M.; Strey, R. Langmuir

$1985,1,718$.

(37) Kahlweit, M.; Strey, R.; Haase, D. J. Phys. Chem. 1985, 89, 163.

(38) Kahlweit, M.; Strey, R.; Firman, P.; Haase, D.; Jen, J.; Schomacker,

R. Langmuir 1988, 4, 499.

(39) Kahlweit, M.; Strey, R.; Schomacker, R.; Haase, D. Langmuir 1989, $5,305$.

(40) Wilcoxon, J. P. J. Phys. Chem. 1990, 94, 7588

(41) Shivaji Sharma, K.; Patil, S. R.; Rakshit, A. K. Colloids Surf., A 2003, 219, 67.

(42) Shiundu, P.; Giddings, J. J. Chromatogr., A 1995, 715, 117.

(43) Forster, S.; Schmidt, M. 1995, Advances in Polymer Science; Springer Verlag: Berlin, 1995; Vol. 120, pp 51-133. 
(44) Sedlák, M. J. Chem. Phys. 1996, 105, 10123.

(45) Sedlák, M. J. Chem. Phys. 2005, 122, 151102.

(46) Muthukumar, M. J. Chem. Phys. 1997, 107, 2619.
(47) Muthukumar, M. J. Chem. Phys. 1996, 105, 5183.

(48) Israelachvili, J. N. Intermolecular and Surface Forces; Academic Press: Amsterdam, 1991. 